Revista de

Contabilidade e

Organizações
DOI: http://dx.doi.org/10.11606/issn.1982-6486.rco.2018.148286
Journal of

Accounting and

Organizations

\title{
Caso para ensino: o processo de escolhas metodológicas em uma abordagem quantitativa
}

Teaching case: the process of methodological choices in a quantitative approach

Jeferson Lana ${ }^{\text {a }}$ Raul Beal Partyka ${ }^{\text {a }}$; Anete Alberton ${ }^{\text {a }}$, Rosilene Marcon ${ }^{\mathrm{a}}$

${ }^{\mathrm{a}}$ Universidade do Vale do Itajai

Palavras-chave

Métodos de pesquisa.

Escolhas metodológicas.

Técnicas de análise.

\begin{abstract}
Resumo
O caso para ensino trata do processo de amadurecimento de um problema de pesquisa no programa de mestrado em Administração e Contabilidade, no paradigma positivista, em uma abordagem quantitativa. $\mathrm{O}$ caso adota uma narrativa e diálogos típicos entre um aluno de mestrado e seu orientador e professores, para expor os pontos de tensão e escolhas que emergem no primeiro ano de um típico programa de mestrado na área. $\mathrm{O}$ caso permite ao aluno conhecer uma típica interação no mestrado na área e refletir sobre a sequência de escolhas de técnicas estatísticas específicas. $\mathrm{O}$ caso de ensino é sugerido para disciplinas como metodologia de pesquisa, métodos quantitativos, seminários de dissertação no mestrado, e também para iniciação científica.
\end{abstract}

Keywords

Research Methods.

Methodological choices.

Techniques of analysis.
Informações do Artigo

Recebido: 17 de julho de 2018

Aceito: 05 de dezembro de 2018

Publicado: 10 de dezembro de 2018

\begin{abstract}
This teaching case focus on the process to mature a research problem in a master in Administration and Accounting, considering in a quantitative approach in a positivist paradigm. The case embrace typical dialogues and narratives between a master's student and his supervisor and other professors, to expose the points of tension and choices that emerge in the first year of a typical master's degree. This case allows students to explore a typical interaction in the master's degree and to reflect on the sequence of choices for ordinate the specific statistical techniques. We suggest this teaching case for disciplines such as research methodology, quantitative methods, dissertation seminars in the master's degree, and for undergraduate researches.
\end{abstract}

\section{Implicações práticas}

Este caso para ensino serve como apoio às escolhas metodológicas em projetos de pós-graduação nos cursos de Administração e Contabilidade. O caso para ensino propõe um dilema sobre escolhas metodológicas em uma abordagem quantitativapositivista, e aborda a adequação dessas escolhas ao processo de amadurecimento do problema de pesquisa e da teoria de suporte.

Copyright (C) 2018 FEA-RP/USP. Todos os direitos reservados

\section{CASO}

Leonardo é um jovem de 24 anos, mestrando em Administração de Empresas. Além das disciplinas obrigatórias e optativas que está cursando, também faz parte de um dos grupos de pesquisa de sua universidade. Esse grupo realiza pesquisas sobre Estratégia e Desempenho Empresarial. Sua dissertação está sendo desenvolvida sobre os mecanismos internos e externos de Governança Corporativa. O tema de pesquisa é algo que ele traz no seu histórico, pois desde a graduação acompanha de perto as empresas listadas na bolsa de valores B3 e todas as estruturas de governança corporativa. Entrou no mestrado procurando exatamente o que o curso pode lhe proporcionar: o aprofundamento do tema e a elaboração de pesquisas científicas no contexto brasileiro.

Autor Correspondente: Tel. (47) 3314-7500

E-mail: jlana@univali.br (J. Lana); raul@edu.univali.br (R. B. Partyka); anete@univali.br (A. Alberton); rmarcon@univali.br (R. Marcon)

Universidade do Vale do Itajaí (Univali). R. Uruguai, 458 - Centro, Itajaí - SC, 88302-901 Brasil. 
Os alunos que participam do grupo de pesquisa junto com Leonardo, são mestrandos e doutorandos, além de alguns professores de áreas relacionadas ao tema do grupo. No grupo ele tem espaço para discutir com os participantes sobre as ideias, teorias e metodologias que pretende utilizar em seu trabalho. Em um dos encontros do grupo, Leonardo teve o primeiro contato com o Professor Dr. Rubens, que se tornaria seu orientador durante o mestrado.

\section{UM LONGO CAMINHO COMEÇA PELO PRIMEIRO PASSO}

No primeiro encontro entre orientando e orientador, houve a apresentação da ideia inicial do projeto da dissertação de Leonardo, e o jovem pode expressar suas preocupações ao orientador:

- Professor, li os seus três artigos mais recentes. O senhor tem muito conhecimento e experiência em governança corporativa, tenho muito interesse nesse tema. Eu gostaria de estudar a relação dos mecanismos externos de governança corporativa na performance das empresas brasileiras listadas. Esse é meu objetivo de pesquisa. Mas, tenho dúvida quanto ao método que devo utilizar.

- Realmente é um tema muito interessante, Leonardo - disse o professor Rubens - Há um extenso campo de pesquisa e muito trabalho a ser feito. O tema de governança corporativa é bastante amplo na literatura. Embora os estudos de governança corporativa sejam relativamente novos, as teorias subjacentes, como Teoria da Agência e Teoria dos Custos de Transação, já são amplamente difundidas e bastante maduras. Com isso, pesquisas mais exploratórias quantitativas podem ter menos valor. Pesquisas causais podem ser mais apropriadas. É lógico que tudo isso vai depender também da sua questão de pesquisa. Vou explicar para você o processo, especificamente dos métodos quantitativos, que me parece ser adequado a seu caso. Você comentou que pretende analisar o relacionamento entre duas (ou mais) variáveis, então vamos partir por aí. É como um funil - disse o professor, tomando uma caneta e uma folha em branco em suas mãos.

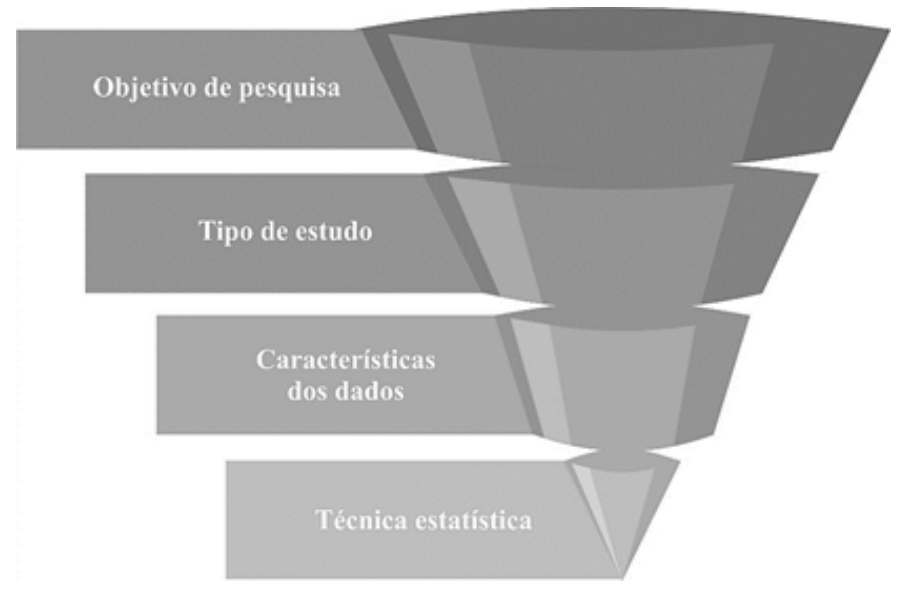

Figura 1. Processo para escolha metodológicao

Fonte: elaborado pelos autores com base em Cooper \& Schindler (2016).

O professor Rubens desenhou o que seria, a partir de então, a figura que guiaria os passos de Leonardo na sua jovem carreira de pesquisador. Antes de deixar o jovem ainda mais nervoso, o professor acrescentou:

- Este será o seu guia, Leonardo. Quando souber as respostas para as quatro fatias do funil, você chegará ao método e técnicas adequados à sua pesquisa. Já podemos ter alguma ideia da primeira e da segunda fatia. $O$ objetivo de pesquisa você já me falou. Já quanto o tipo de estudo são quatro as categorias: informativo, descritivo, explanatório e preditivo. Você precisa dedicar algum tempo para amadurecer isso, Leonardo. Você vai apontar direções para onde deve caminhar o desempenho a partir dos mecanismos de governança? Ou vai descrever os dados passados para encontrar padrões? O seu método de estudo precisa estar condizente com seu objetivo central. Não adianta você formular hipóteses explicativas deduzidas a partir da teoria, em um estudo hipotéticodedutivo, e apenas descrever os dados na dissertação. Da mesma forma, não faz sentido propor estudos descritivos e querer utilizar métodos sofisticados de explicações causais com controle de endogeneidade e aleatorização. Pense em seu trabalho como uma linha de produção de uma empresa. Os processos precisam estar alinhados e muito bem justificados. 
- Certo, vou pesquisar e tentar delinear melhor o trabalho. Obrigado pela ajuda professor, acredito que agora as coisas vão ficar mais claras. Disse o jovem ainda absorvendo tamanha quantidade de informação e pensando no trabalho que ainda tem pela frente.

- Leonardo, para o encontro do grupo do próximo mês, sugiro que você apresente o esboço da sua intenção de pesquisa, disse o orientador. Explicar para o grupo do que se trata o trabalho e como você pretende desenvolvê-lo pode ajudar a amadurecer essas questões.

- Claro, mas o que precisamente devo apresentar, professor?

- Olha, você pode apresentar seu objetivo, teorias a serem utilizadas para dar suporte a suas hipóteses eo esboço do método que pretende utilizar. Coisas como características dos dados que você pretende usar, abordagem e técnica de análise dos dados. Pode seguir a lógica do funil e buscar subsídio nos livros do Hair et al. (2005), Black (1999) e Cooper e Schindler (2016). Com o desenvolvimento da pesquisa, tudo isso pode ser alterado, mas acho que é uma boa maneira de começar.

- Combinado professor, vou preparar a apresentação. Respondeu Leonardo tentando não transparecer sua insegurança com relação a seu trabalho, principalmente com relação aos aspectos metodológicos.

Os encontros e reuniões entre Leonardo e seu orientador estavam no estágio inicial. O Professor Rubens costuma não ser muito exigente com seus orientandos no primeiro semestre, para que eles tenham mais tempo para cursar as disciplinas. Leonardo era um aluno dedicado, já tinha conhecimento sobre o tema da pesquisa, que muito o empolgava, porém, a angústia se dava sempre com relação à metodologia. Ele sabia que o trabalho caminharia para um paradigma mais positivista, mas não fazia ideia de qual técnica seria a mais apropriada.

"Não sei o que vou fazer! Só no livro do Hair são mais de dez tipos diferentes de técnicas estatísticas multivariadas. Juntando as univariadas, já perdi a conta. Como é que vou decidir isso, minha Nossa Senhora do A1? ", pensou Leonardo, fazendo referência às expressões com que ele e seus amigos costumavam brincar.

\section{O INÍCIO, O FIM E O MEIO}

Uma semana se passou, e em meio aos trabalhos e atividades do mestrado, Leonardo dedicou pouco tempo de estudo em sua dissertação. Como restavam menos de dois meses até o encontro do grupo de pesquisa, ele resolveu pedir ajuda a um de seus professores. Durante o intervalo das aulas, no corredor da universidade, procurou o Professor Dr. Oliveira que, além de ensinar métodos quantitativos, também fazia parte do mesmo grupo de pesquisa:

- Professor Oliveira, com licença! Estou com dificuldades para encontrar o melhor método para analisar os meus dados. Já conheço e sei trabalhar com três técnicas estatísticas, mas elas me parecem insuficientes. Eu deveria utilizar algum desses métodos que já conheço? Encontrei dois ou três estudos que utilizaram esses métodos, mas ainda não sei qual a melhor opção. Qual técnica estatística se relaciona melhor com cada um dos quatro tipos de estudo quantitativo?

- Calma lá, garoto. A escolha da metodologia precisa ser feita com calma, e depois de muita reflexão e estudo. É um passo muito importante durante o desenvolvimento do estudo, porque compromete toda a análise dos resultados. Ela não pode ser feita por conveniência, mas sim pela melhor adequação ao seu objetivo de pesquisa, a sua área de colaboração, às características dos dados, entre outros fatores. O fato de você entender de análise fatorial não faz com que ele seja adequado a seu estudo. A escolha precisa ser derivada da sua questão de pesquisa, do nível de maturidade da sua teoria e das características dos dados a que você tem acesso. Você já sabe ou já possui os dados que irá utilizar?

- Sim, desde que entrei no mestrado, me dediquei a coletar os dados pelo menos um dia por semana. Por isso, já coletei um periodo de 14 anos de dados das empresas listadas na bolsa brasileira. Talvez ainda precise coletar outros dados, mas tenho certeza que a minha base já está bastante satisfatória.

- Certo. Então você poderia rodar seus dados em um software de análises estatísticas, para antes de tudo, identificar se é uma amostra de dados com distribuição normal ou não.

- Essa palavra não me é estranha. Já encontrei essa classificação para a amostra, nos livros que o Professor Rubens me indicou. 
- É uma importante classificação inicial. Algumas técnicas estatísticas, por exemplo, funcionam apenas com dados cujas distribuições sejam paramétricas. A distribuição normal é um exemplo. Já outras técnicas, servem exclusivamente para dados com distribuições não paramétricas, que não respeitam qualquer ordem de distribuição. Depois você pode avançar e, baseado na literatura, encontrar as demais classificações, como, por exemplo, se são heteroscedásticos? Também, como será a coleta? Survey ou dados secundários? Se você pretende utilizar algum tratamento que aproxime os resultados de causalidade e mitigue problemas de endogeneidade ou será uma pesquisa relacional? Quais técnicas os estudos da sua área têm utilizado e por quê?

Leonardo utilizou de seus conhecimentos prévios da disciplina de métodos de pesquisa, e identificou como sugerido pelo professor Oliveira, que seus dados tinham distribuição normal. Leonardo ficou ainda mais confuso depois da conversa. Agora, além da técnica, precisaria entender o que significavam aqueles termos.

“Heteroscedáticos? Endógenos? Onde é que fui me enfiar!”, pensou ele.

Dentre os trabalhos que conhecia sobre governança corporativa, poucos utilizavam as técnicas estatísticas que dominava. Decidiu continuar a tarefa indicada pelo seu orientador e ler mais artigos sobre seu tema. Assim, mergulhou nos três livros indicados e nos artigos que havia encontrado como referências para desvendar o método mais adequado. A cada página, descobria mais. Estava empolgado!

\section{HÁ UMA LUZ NO FIM DO TÚNEL}

O prazo continuou a correr e foi 'asfixiando' ainda mais Leonardo. Faltando pouco mais de um mês para o encontro do grupo de pesquisa, ao final da aula de métodos quantitativos, Leonardo pediu ao Professor Dr. Gomes, que ministrava a disciplina, que lhe desse algum conselho quanto ao método e técnicas que deveria utilizar e sobre outras indicações. Estava cada vez mais confuso e agora não havia muito tempo.

- Professor, vou apresentar meu projeto para o meu grupo de pesquisa. E meu orientador pediu um esboço da minha intenção de pesquisa. Mas, ainda estou com dúvida sobre o método. O Sr. pode me ajudar?

- Claro. - Respondeu o professor. Já estava acostumado a ajudar os alunos com dúvidas na metodologia. - Você é o orientando do Rubens, certo? O que quer pesquisar a relação dos mecanismos de governança com o desempenho das empresas? Diga lá, como são os seus dados?

- Então, como eu havia comentado com o Prof. Oliveira, eu tenho coletado dados desde que entrei no mestrado. Talvez ainda precise coletar mais, mas já tenho um bom volume. São dados secundários com distribuição normal. Pretendo apenas relacionar as variáveis dependentes (desempenho) com as independentes, relativas aos mecanismos internos e externos de governança corporativa - disse ele orgulhoso por conhecer a classificação. Estou terminando as últimas atividades da disciplina de métodos quantitativos, conheço alguns métodos e até testei algumas relações com estes meus dados. Fiz alguns Testes Te ANOVA.

- Bom, você já avançou um pouco. Então, eu recomendo que você faça uma pesquisa bibliométrica sobre seu tema. Ela irá nortear você e indicar qual o método e a técnica estatística mais utilizada pelos pesquisadores da sua área e em consequência qual a mais adequada. Tanto a pesquisa quantitativa, quanto a qualitativa, podem ser usadas para análises confirmatórias. Por exemplo, você poderia utilizar estudo de caso, análise de conteúdo na pesquisa qualitativas. Poderia também utilizar regressão linear múltipla ou outras técnicas sofisticadas de análise quantitativa. Analise os resultados da sua pesquisa bibliométrica para ajuda-lo nessas definições. Outro fator determinante para a escolha, é seu objetivo de pesquisa e as características de seus dados. Me parece que uma estatística univariada não vai te ajudar muito. Acredito que você precise incluir variáveis de controle, não sei se você e seu orientador já definiram quais serão. Com isso, técnicas de análise multivariada de dados são mais adequadas. Faça a bibliométrica. Você entenderá do que estou falando. E não se preocupe, é normal estar confuso sobre as questões metodológicas neste estágio inicial da pesquisa - disse o Professor Gomes.

A ideia do professor realmente parecia boa. "Vou parar de ler apenas os artigos seminais e mais citados e vou investigar como está a publicação sobre este tema". Com a busca na base Web of Science, Leonardo encontrou 249 artigos, o suficiente para deixá-lo ainda mais preocupado.

"Como vou ler todos esses trabalhos sobre meu tema para encontrar o método mais utilizado? E mesmo que eu encontre, será que esse método também vai servir para a minha dissertação? Quando foi mesmo que eu achei que esse mestrado seria uma boa ideia? Socorro! Quanto tempo ainda tenho? Um mês??? Não vai dar tempo!!!". 
Leonardo criou um cronograma de atividades diárias para que conseguisse executar a tarefa o quanto antes. Ele queria ter certeza de que os dados seriam úteis para confirmar suas hipóteses de pesquisa. Assim, lendo mais sobre o assunto e seguindo a indicação do Prof. Gomes, foi encontrando diversas técnicas que, segundo ele, poderiam ser adequadas à sua pesquisa. De maneira geral, os resultados dos estudos anteriores têm grande incidência na utilização de regressão.

Durante suas tarefas, em meio a tantos artigos, o colega Marcelo, que também fazia parte do grupo de pesquisa, se aproximou de Leonardo na sala de estudos da universidade, e, curioso, perguntou:

- Leonardo, no que você tanto trabalha?

- Estou fazendo uma pesquisa bibliométrica para identificar o método e a técnica estatística mais adequada para minha dissertação. Estou certo de que meu trabalho será quantitativo. Olha só, de 249 artigos, todos os que buscam analisar as relações similares às minhas, usam métodos quantitativos. A minha dúvida agora é sobre a escolha da técnica estatística.

- Entendi. E você pretende utilizar essa técnica que você encontrar, porque ela é a mais usada? Tipo, a maioria vence?

- Não, acho que vou inovar, Marcelo. Até agora, a regressão é a mais utilizada nos artigos. Se ao final ela se mantiver como a mais utilizada, vou propor algo revolucionário, algo completamente novo. Pode ser, por exemplo, a análise de variância multivariada, a MANOVA.

- Veja bem, Leonardo. Se a regressão é a técnica que mais aparece, existe um motivo justificável para isso. Estamos fazendo ciência, e não podemos querer criar algo sem a devida justificativa, apenas porque queremos inovar. A inovação do método precisa seguir um roteiro científico justificado e, mais importante, aceito.

- É, acho que estou sendo ingênuo - disse Leonardo começando a entender a complexidade que uma evolução cientifica requer.

Momentos como este, de querer provocar a inovação na área de pesquisa, e também de crises existenciais eram comuns a Leonardo. Ainda assim, ele não desanimou. Continuou com suas buscas. Uma vez terminado o levantamento, ele poderia entregar para o orientador o resultado encontrado e, juntos, definirem os próximos passos.

Passados alguns dias, Leonardo termina sua pesquisa bibliométrica e elabora uma pequena carta de resultados. Está angustiado, mas isso já não é nenhuma novidade. Tudo é muito novo. A falta de experiência em pesquisas, a complexidade que circunda essas decisões e a insegurança natural de um jovem produziam o ambiente ideal para as angustias que estava vivendo. Mas, ele havia terminado enfim a pesquisa bibliométrica e tinha os resultados em mãos. O que ele teria encontrado?

\section{REFLEXÕES}

Leonardo queria levar algo definido, com base na sua pesquisa bibliométrica. Um dia antes de apresentar para a turma do grupo de pesquisa, ele decidiu falar com o Professor Rubens, seu orientador. Incerto se o trabalho que elaborou representava uma saída para identificar o método adequado de sua dissertação, ele chegou à porta do Professor Rubens. Leonardo respirou fundo, segurou o ar por alguns segundos, e tomou coragem e bateu à porta:

- Quem é? Perguntou o professor Rubens de dentro da sala.

- É o Leonardo. Respondeu.

- Pode entrar.

A sala parecia menor.

- E aí, tudo pronto para amanhã? Perguntou o orientador.

- Gostaria de lhe mostrar o resultado de uma pesquisa bibliométrica que fiz. Essa pesquisa me ajudou a identificar qual o método e a técnica estatística mais utilizados nos artigos semelhantes ao que quero desenvolver, relacionando mecanismos externos de governança corporativa.

- Então, o que você encontrou? 
- Após uma extensa pesquisa da literatura, o método mais utilizado e adequado aparentemente é o hipotético-dedutivo. Basicamente, 92\% dos artigos são quantitativos e, destes, $73 \%$ utilizam desenvolvimentos de hipóteses a serem testadas. A regressão linear múltipla foi a técnica estatística que mais apareceu (64\%), com o uso de estimadores como MQO (mínimos quadrados ordinários) e MMG (método dos momentos generalizados). Posso utilizar dados em painel, assim como os diversos artigos que encontrei na bibliometria. Penso que meus dados se enquadrem nessas características. Vou criar hipóteses a serem testadas, certo? Também tenho dados em painel com múltiplas variáveis. Mas eu queria muito inovar, Professor. Utilizar uma técnica estatística diferente. Eu sei que isso requer maiores justificativas, mas se eu usar o que todos estão usando, meu estudo não será apenas mais um?

O professor Rubens ficou surpreso com o esforço empreendido por Leonardo e por seu interesse em inovar. Se arrumou em sua cadeira, levou uma das mãos ao queixo e, olhando o horizonte, disse:

- Hummm...

Enquanto os olhos do professor Rubens buscavam um ponto indeterminado, Leonardo olhava fixamente para o computador, para a tabela com seus achados. Será que o processo que havia realizado para encontrar o melhor método foi adequado? Conversar com os professores do programa e colegas, trouxe benefícios ou apenas o confundiu mais? Pesquisas bibliométricas são mesmo necessárias? Para que? E, o que dizer de sua angústia por inovar na escolha do método e técnicas? É um caminho que vale a pena seguir dadas as características da pesquisa?

\section{NOTAS DE ENSINO}

As notas de ensino são para acesso dos docentes que usarão o caso em sala de aula. Ainda, é recomendável que o caso para ensino seja testado em sala de aula, nas mesmas condições de ensino para as quais o caso foi concebido. Pode sofrer alterações e aprimoramentos após o resultado do teste (Roesch, 2007). O professor mediador também pode selecionar os eixos temáticos presentes nessas notas e aplicar em cada aula específica.

\section{Objetivos educacionais}

O caso apresentado foi estruturado de forma a possibilitar a discussão entre alunos e professores e direcionar metodologicamente os trabalhos na fase inicial de elaboração. O caso busca a identificação dos leitores com os personagens no caso, seja o aluno, o doutorando que auxilia os colegas, o professor que sugere caminhos, o professor de metodologia ou ainda o professor orientador.

Com base em três eixos temáticos, espera-se a seguinte compreensão educacional:

1) O processo de amadurecimento empírico e teórico do aluno;

2) Aprofundamento do conhecimento técnico de métodos quantitativos;

3) Conhecimento da adequação do método estatístico ao objetivo de pesquisa e aderência do modelo proposto à comunidade que pesquisa sobre determinado fenômeno.

Os dados que constituem o presente caso foram criados de forma lúdica, assim como o enredo é adaptado, com base em acontecimentos reais, relatados por professores e alunos de um programa de mestrado e doutorado acadêmico em Administração, entretanto, se faz presente em outros programas e áreas. As fontes utilizadas foram conversas informais com professores de mestrados e doutorados na área de ciências sociais, relatos de alunos do programa e experiências vivenciadas pelos autores deste caso. Todos os nomes dos personagens são fictícios. $\mathrm{O}$ caso foi aplicado e testado em uma aula da Disciplina de Métodos, em um programa de Mestrado.

\section{Utilização do caso}

O caso é destinado aos alunos dos cursos de mestrado acadêmico nas áreas de Administração, Ciências Contábeis e áreas relacionadas. Pode ser aplicado em disciplinas específicas como: metodologia, métodos quantitativos e seminários de dissertação. 


\section{Sugestão para plano de ensino}

O respectivo caso pode ser analisado em sala de aula em grupos de no mínimo dois e no máximo, cinco alunos. Não é recomendado aplicar o caso individualmente, pois em grupo os alunos irão debater as perguntas e identificarão as escolhas possíveis, as dúvidas e seus temores com relação a seus próprios trabalhos. É por meio de um debate em grupo, que o entendimento do caso tanto individual quanto coletivamente é enriquecido. O Quadro 1 apresenta o primeiro plano de aula sugerido, com seções identificando o tempo necessário, o objetivo e atividade a ser desenvolvida.

\begin{tabular}{|c|c|c|}
\hline Momento & Objetivo & Atividade \\
\hline Apresentação & $\begin{array}{l}\text { Com o objetivo de alcançar respostas mais realistas e } \\
\text { coerentes, sugere-se uma leitura prévia dos principais } \\
\text { conceitos relacionados aos métodos quantitativos. }\end{array}$ & Leitura e discussão \\
\hline Desenvolvimento & $\begin{array}{l}\text { O intuito dessa parte é promover um debate que envolva } \\
\text { todos os alunos, gerando reflexões sobre o dilema que } \\
\text { circunda os acadêmicos de mestrado na escolha adequada } \\
\text { da metodologia de seus respectivos trabalhos de conclusão. }\end{array}$ & $\begin{array}{l}\text { Cada grupo apresenta, ao professor } \\
\text { e à sala, os pontos mais relevantes } \\
\text { da discussão e conclusões às quais } \\
\text { chegaram com relação ao dilema }\end{array}$ \\
\hline Finalização & $\begin{array}{l}\text { Há } 3 \text { eixos com duas perguntas em cada. Sugere-se dividir } \\
\text { a turma em três grupos, cada um responsável por uma } \\
\text { abordagem. O professor será mediador e deverá intervir } \\
\text { junto aos dois grupos ouvintes, debatendo sobre as } \\
\text { melhores decisões e escolhas por parte do grupo que está } \\
\text { apresentando. }\end{array}$ & Discussão das questões sugeridas \\
\hline
\end{tabular}

Quadro 1. Plano de aula sugerido em sala.

Fonte: elaborado pelos autores.

\section{Questões sugeridas para discussão por eixos temáticos}

\section{Eixo 1 - Processo de amadurecimento empírico e teórico do aluno}

1a) De que forma a apresentação dos trabalhos no grupo de pesquisa pode contribuir com o desenvolvimento do aprendizado de Leonardo e de seus colegas?

1b) O que o Professor Oliveira quis dizer com "A escolha metodológica [...] não pode ser feita por conveniência”? Quais os riscos que essa escolha poderia trazer para Leonardo?

\section{Eixo 2 - Conhecimento técnico de métodos quantitativos}

2a) Por que o Professor Oliveira estava interessado em saber sobre a distribuição dos dados de Leonardo? E se fossem dados não normais, quais decisões restariam para ele?

2b) Quais cuidados deveriam ser tomados por Leonardo para fazer uma pesquisa causal e não a relacional como ele propôs? A regressão linear multivariada ainda seria uma opção válida caso esses cuidados fossem tomados? Justifique.

Eixo 3 - Adequação do método estatístico ao objetivo de pesquisa e aderência do modelo de pesquisa proposto sobre o fenômeno

3a) Aponte os motivos e os benefícios (caso haja) pelos quais o Professor Gomes recomendou a Leonardo o uso da pesquisa bibliométrica como ferramenta adicional da escolha metodológica.

3b) Considerando a escolha pelo método quantitativo, avalie se o direcionamento indicado pela pesquisa bibliométrica é adequado para que Leonardo possa atingir o objetivo de sua pesquisa. Leonardo poderia utilizar uma técnica diferente daquilo apontado pela bibliométrica? 


\section{Análises, direcionamentos e reflexões para auxílio na resolução do caso}

\section{Eixo 1 - Processo de amadurecimento empírico e teórico do aluno}

1a) De que forma a apresentação dos trabalhos no grupo de pesquisa pode contribuir com o desenvolvimento do aprendizado de Leonardo e de seus colegas?

É uma importante contribuição, sobretudo para debater os confounding factors, ou seja, os fatores que podem gerar confusão na hora de se determinar as variáveis do estudo. Para Manski (1993) um primeiro conjunto de fatores de confusão é gerado pela possibilidade de os dados observacionais não permitirem controlar totalmente os atributos.

Quanto às variáveis, quando são bem especificadas, as independentes e dependentes, o desenho empírico de um estudo precisa controlar os fatores de confusão. Se não controlado, resultados aparentemente significativos podem não ser verdadeiros (Armstrong \& Shimizu, 2007).

Além da definição das variáveis, a apresentação de trabalhos em grupos de pesquisa permite a interação entre os alunos e a evolução dos aspectos teóricos e metodológicos, por meio de feedbacks daqueles alunos que já se encontram em fase de elaboração da dissertação e que já passaram por anseios semelhantes àqueles de Leonardo.

Por isso, é importante que o professor potencialize que o grupo tenha momentos como: a apresentação do desenvolvimento da dissertação alunos, depoimentos e feedbacks de colegas em diferentes estágios do trabalho, discussões acerca de aspectos teóricos foco do grupo de pesquisa, discussão sobre aspectos metodológicos, bem como discussão de artigos, métodos e técnicas de pesquisa, a utilização de softwares que auxiliam e suportam análise de dados (exemplos como R, Stata, ATLAS.ti, MAXQDA, NVivo, IRAMUTEQ, entre outros), bem como os de automatização do processo de pesquisa (softwares para citações, organização de referências, revisão e editoração do manuscrito, como por exemplo: Mendeley, Zotero, EndNote, Latex, entre outros).

2b) O que o Professor Oliveira quis dizer com “A escolha metodológica [...] não pode ser feita por conveniência"? Quais os riscos que essa escolha poderia trazer para Leonardo?

A escolha do método não pode ser feita por conveniência, por ser o único método que o autor sabe utilizar ou porque é o método que mais o agrada. A escolha depende de um formato que permita responder à questão de pesquisa de forma parcimoniosa (Cooper e Schindler, 2016). Ser parcimonioso diz respeito a evitar esperar que a técnica multivariada "arrume" as variáveis relevantes, cuidando para que variáveis irrelevantes, que podem aumentara habilidade da técnica de ajustar os dados da amostra, não sobreajuste os dados e torne os resultados menos generalizáveis à população. Isso pode provocar o aumento do grau de multicolinearidade, o que torna a interpretação de todas as variáveis mais complicada (Hair et al., 2009).

Opiniões não devem ser usadas quando evidências mais confiáveis estiverem disponíveis em fontes documentais ou por observação direta. Além disso, esforços devem ser feitos para minimizar a influência do viés pessoal na seleção e registro de dados. A análise dos dados deve ser suficientemente extensa para revelar seu significado. Tais dados devem ser classificados de maneiras que ajudem o pesquisador a chegar a conclusões pertinentes e revelem claramente os resultados que levaram a essas conclusões. Quando métodos estatísticos são usados, técnicas descritivas e inferenciais apropriadas devem ser escolhidas, a probabilidade de erro deve ser estimada e os critérios de significância estatística aplicados (Cooper \& Schindler, 2016). Sendo que, o autor deve sempre evidenciar claramente todos estes passos em seu estudo.

\section{Eixo 2 - Conhecimento técnico de métodos quantitativos}

2a) Por que o Professor Oliveira estava interessado em saber sobre a distribuição dos dados de Leonardo? E se fossem dados não-normais, quais decisões restariam para ele?

Uma vez definido o método de pesquisa, passa-se a escolher a técnica estatística e o teste estatístico mais adequado para cada caso. Dentre os aspectos que norteiam a escolha da técnica estatística, podem ser citados: a métrica das variáveis (se são numéricas ou categóricas), a distribuição dos dados (normal ou outra), o teste associado ao tipo de distribuição (teste-t, F, Mann-Whitney, Wilcoxon, entre outros) (Cooper \& Schindler, 2016, Hair Jr., 2005). Com a resposta da distribuição de dados, Leonardo poderia limitar o leque de escolhas de testes e técnicas estatísticas adequadas ao seu objetivo de pesquisa. 
Se os dados não forem normais, algumas técnicas estatísticas não são apropriadas. Cada uma das técnicas e testes estatísticos existentes possuem pressupostos teóricos pré-definidos que devem ser respeitados para uma estimação inferencial não enviesada e consistente. Logo, perguntas referentes à natureza dos dados, como a do Prof. Oliveira, sobre a distribuição normal, servem para a reflexão do aluno sobre técnica e teste mais adequados para seu caso. Leonardo também deve buscar formas de, quando necessário, atenuar condições como a nãonormalidade dos dados, foco desta questão, ou mesmo condições mais graves sobre a eficiência estatística de suas escolhas, como a heterocedasticidade.

Por exemplo, para atenuar uma condição de não-normalidade, transformações podem ser aplicadas em variáveis dependentes, independentes ou ambas. A técnica de transformação de variáveis, como calcular o logaritmo ou a raiz quadrada da variável e assim criar uma nova variável, ajuda a eliminar a característica indesejável e permite uma medida melhor da relação.

O tamanho da amostra também pode ajudar a diminuir condições de não normalidade, uma vez que, pelo Teorema do Limite Central, com variáveis contínuas e amostras maiores que 30, a normalidade deixa de ser uma condição fundamental. Amostras maiores reduzem os possíveis efeitos nocivos da não-normalidade (Hair et al., 2009). O autor deve considerar que os algoritmos por trás de cada técnica pressupõe alguns determinantes amostrais, como tamanho mínimo da amostra, distribuição, entre outros.

2b) Quais cuidados deveriam ser tomados por Leonardo para fazer uma pesquisa causal e não a correlacional como ele propôs? A regressão linear multivariada ainda seria uma opção válida caso esses cuidados fossem tomados? Justifique.

A questão remete à seguinte passagem no texto: "Então, como eu havia comentado com o Prof. Oliveira, eu tenho coletado dados desde que entrei no mestrado. Talvez ainda precise coletar mais, mas já tenho um bom volume. São dados secundários com distribuição normal. Pretendo apenas relacionar as variáveis dependentes (desempenho) com as independentes, relativas aos mecanismos internos e externos de governança corporativa disse ele orgulhoso por conhecer a classificação".

A hipótese relacional descreve a relação entre duas variáveis, neste caso a pesquisa pretende descrever uma relação entre duas ou mais variáveis (Cooper e Schindler, 2016). Leonardo procurava a existência apenas de uma implicação de que as variáveis ocorrem em algum relacionamento previsível.

Já o objetivo de pesquisa, quando causal, deve propor que uma variável de alguma forma é responsável pelo comportamento da outra. A variável causal, tipicamente chamada de variável independente não precisa ser a única fonte de influência no comportamento da variável dependente (Cooper \& Schindler, 2016), isso poderá ser investigado ao longo da pesquisa.

Logo, Leonardo deveria buscar um desenho de pesquisa em que as covariações da regressão são apresentadas como relações causais, incluindo variáveis de controles importantes na análise da relação proposta. Além disso, os parâmetros estimados em ciências sociais são, por natureza, endógenos. Isso implica que há variáveis que definem as escolhas empresariais, por exemplo, que não são aleatórias. Essa falta de randomização na variável de tratamento principal impede que ela possa ser entendida como "causa e efeito", quando comparada a um grupo de controle. Para isso, Angrist \& Pichke (2015) sugerem o uso de desenhos de pesquisa que, ainda que não sejam causais por essência, se aproximam da causalidade por trazer desenhos de aleatorização da variável de interesse. Desenhos de pesquisa como a regressão descontínua, diferenças das diferenças, variáveis instrumentais e matching permitem que o modelo exclua explicações alternativas (Angrist \& Pischke, 2015). Ou ao menos boa parte delas.

Ainda, em uma pesquisa dita causal, a inclusão de dados em painel com controle de efeitos fixos, aliados a algum quase experimento (exemplos acima), entre outras opções podem permitir o controle de parte da endogeneidade atribuída aos modelos em ciências sociais e melhorar a interpretação dos resultados obtidos. Ainda assim, é preciso ter em mente que controles estatísticos e desenhos quase-experimentais apenas atenuam o problema da endogeneidade. A inferência da causalidade dependerá de demais controles, replicabilidade e validade externa dos achados.

\section{Eixo 3 - Adequação do método estatístico ao objetivo de pesquisa e aderência do modelo de pesquisa proposto sobre o fenômeno}

3a) Aponte os motivos e os benefícios (caso haja) pelos quais o Professor Gomes recomendou a Leonardo o uso da pesquisa bibliométrica como ferramenta auxiliar para a escolha metodológica. 
O estudo quantitativo de um referencial teórico, em um tema, recebeu diferentes nomes. A adoção do termo "bibliométrico" é comumente atribuída a Pritchard (1969, p. 348) como "a aplicação de métodos matemáticos e estatísticos a livros e outros meios de comunicação". Um conceito mais atual é dado por Van Leeuwen (2004, p. 374) como sendo "o campo da ciência que lida com o desenvolvimento e aplicação de medidas e indicadores quantitativos para a ciência e tecnologia, com base em informações bibliográficas."

Dentre os motivos para utilização do método podem ser citados : a) a capacidade de fornecer uma visão geral da estrutura intelectual das publicações; b) a possibilidade que a análise leve à identificação de estruturas e padrões significativos em, por exemplo, autoria, periódicos, questões de pesquisa, teorias e amostras e descobertas geográficas e; c) o potencial para a confirmação quantitativa de categorias derivadas subjetivamente em avaliações publicadas, bem como a possibilidade de explorar o cenário de pesquisa e identificar categorias.

Como benefícios podem ser citados: a) a descoberta do método de pesquisa e técnica estatística mais utilizados naquele tema, logo, os possivelmente mais adequados; b) "deixando de lado os julgamentos de valor, parece clara a importância de se dispor de uma distribuição que nos informe sobre [...] utilidade ou o que mais desejarmos saber" (Price, 1976, p. 39); c) os resultados da pesquisa podem fornecer também, de maneira geral, aspectos qualitativos, como as implicações da análise bibliométrica em relação à avaliação da pesquisa (Herther, 2009).

Com base em métodos bibliométricos, todos os motivos e benefícios acabam por desenvolver um maior nível de análise de tendências de pesquisa, produtividade em diferentes campos ou padrões de conexão científica (Ellegaard \& Wallin, 2005). Por fim, os métodos bibliométricos não substituem a leitura extensiva e a síntese. A bibliometria pode vincular de forma confiável publicações, autores ou periódicos e produzir tabelas, mapas e gráficos de pesquisas publicadas, mas cabe ao pesquisador e seu conhecimento do campo interpretar as descobertas - que é a parte mais difícil.

3b) Considerando a escolha pelo método quantitativo, avalie se o direcionamento indicado pela pesquisa bibliométrica é adequado para que Leonardo possa atingir o objetivo de sua pesquisa. Leonardo poderia utilizar uma técnica diferente da indicada pela bibliometria?

Leonardo agora precisa tomar a decisão sobre a definição metodológica de seu trabalho. Para isso, precisa se atentar a duas informações relevantes que apareceram ao longo do caso: Uma delas, e principal norteadora da escolha, seu objetivo de pesquisa. No início do texto, Leonardo reportou que seu objetivo seria: "a relação dos mecanismos externos de governança corporativa na performance das empresas brasileiras listadas". Logo, precisa de um método que permita mensurar a relação entre variáveis. A segunda informação relevante que apareceu no caso, foi o direcionamento metodológico apontado pela pesquisa bibliométrica, que demonstrou que na sua área de pesquisa os trabalhos são predominantemente quantitativos, hipotético-dedutivos e utilizam a técnica de regressão linear multivariada.

Dessa forma, Leonardo poderia escolher o direcionamento apontado pela pesquisa bibliométrica. A metodologia quantitativa, permite que a relação entre variáveis sugerida no objetivo seja testada. Além disso, o método hipotético-dedutivo é particularmente interessante por permitir a criação de hipóteses a serem testadas estatisticamente. Por fim, a regressão linear múltipla permite que o pesquisador relacione duas ou mais variáveis independentes sobre uma variável dependente. No caso de Leonardo, ele pode adicionar variáveis de controle relevantes para aumentar o poder explicativo do modelo. Por fim, poderia ainda efetuar na própria regressão testes de robustez e de atenuação de endogeneidade, como aqueles de quase-experimentos (Angrist \& Pischke, 2015) já sugeridos, regressão descontínua ou a inserção de uma importante variável instrumental, o que requereria maior criatividade na elaboração do desenho de pesquisa.

Por fim, Leonardo poderia escolher um método alternativo. No entanto, um princípio importante precisa ser levantado em pesquisas acadêmicas: o princípio da parcimônia (Hair et al., 2005). A escolha metodológica se dá por um ajuste, um "methodological fit". Com isso, tal decisão não é uma ciência exata, mas sim uma escolha mais adequada frente às opções disponíveis. Por parcimônia, a adequação do método representa aquela escolha mais simples e suficiente para responder o objetivo proposto. Logo, se o problema de pesquisa de Leonardo requer um teste de relação entre variáveis, a regressão linear múltipla, técnica mais utilizada pelos artigos de sua área (conforme apontado pela bibliométrica), seria a opção mais adequada. 


\section{Análise suplementar}

Os livros de Hair et al. (2005) e Cooper e Schindler (2016) apresentam o assunto, métodos de pesquisa em administração, mesclando teoria e prática. Em especial, na parte "Análise e apresentação de dados", em ambos os livros, pode auxiliar os alunos na solução do presente caso, sobretudo ajudando-os a entender, o que é a pesquisa em administração, os tipos diferentes de estudos e, a distinção entre uma boa pesquisa e aquela realizada sem critérios de qualidade. Embasamento sobre os métodos quantitativos, especificamente, pode ser encontrado com grande propriedade no livro Hair et al. (2009) e, de forma mais abrangente, na obra de Angrist e Pischke (2015) que trata exclusivamente sobre métodos quantitativos na área de ciências sociais, com foco em tratamentos para problemas de endogeneidade.

\section{REFERÊNCIAS}

Angrist, J.D.; \& Pischke, S.J. (2015). Mostly Harmless Econometrics: An empiricist's companion. Princeton University Press: Cambridge.

Armstrong, C.E.; \& Shimizu, K. (2007). A Review of Approaches to Empirical Research on the Resource-Based View of the Firm. Journal of Management, 33, 959-986. DOI: https://doi.org/10.1177/0149206307307645

Black, T.R. (1999). Doing quantitative research in the social sciences: An integrated approach to research design, measurement and statistics. Thousand Oaks, CA: Sage Publications.

Cooper, D.R.; \& Schindler, P.S. (2016). Métodos de pesquisa em administração. 12a ed. Porto Alegre: AMGH.

Ellegaard, O.; \& Wallin, A.J. (2015). The bibliometric analysis of scholarly production: How great is the impact? Scientometrics. 105(3), 1809-1831. DOI: https://doi.org/10.1007/s11192-015-1645-Z

Falk, A.; \& Ichino, A. (2006). Clean Evidence on Peer Effects. Journal of Labor Economics, 24(10, 39-57. DOI: https://doi.org/10.1086/497818

Hair Jr., J.F.; Babin, B.; Money, A.H.; \& Samouel, P. (2005). Fundamentos de métodos de pesquisa em administração. Porto Alegre: Bookman.

Hair Jr., J.F.; Black, W.C.; Babin, B.J.; Anderson, R.E.; \& Tatham, R.L. (2009). Análise multivariada de dados. $6^{\mathrm{a} e d .}$ Porto Alegre: Bookman.

Henderson, R.; \& Cockburn, I. (1994). Measuring competence? Exploring firm effects in pharmaceutical research. Strategic Management Journal, 15, 63-84. DOI: https://doi.org/10.1002/smj.4250150906

Herther, N.K. (2009). Research evaluation and citation analysis: Key issues and implications. The Electronic Library, 27(3), 361-375. DOI: https://doi.org/10.1108/02640470910966835

Manski, C.F. (1993). Identification of endogenous social effects: The reflection problem. Review of Economic Studies, 60(3), 531-42. DOI: https://doi.org/10.2307/2298123

Price, D.S. (1976). O desenvolvimento da ciência: análise histórica, filosófica, sociológica e econômica. Rio de Janeiro: Livros Técnicos e Científicos.

Pritchard, A. (1969). Statistical bibliography or bibliometrics. Journal of Documentation, 25(4): 348-9.

Van Leeuwen, T. (2004). Descriptive versus evaluative bibliometrics. n: Moed, H.F., Glanzel, W.; \& Schmoch, U. (2005), Handbook of Quantitative Science and Technology Research: The Use of Publication and Patent Statistics in Studies of S\&T Systems, Kluwer Academic Publishers, Dordrecht.

\section{Como citar este artigo}

Lana, J.; Partyka, R. B.; Alberton, A.; \& Marcon, R. (2018). Caso para ensino: o processo de escolhas metodológicas em uma abordagem quantitativa. Revista de Contabilidade e Organizações, 12:e148286. DOI: http://dx.doi.org/10.11606/issn.1982-6486.rco.2018.148286 